\title{
NOTAS SOBRE ONTOLOGIA DA LIBERDADE: \\ O MAL E O SOFRIMENTO DE LUIGI PAREYSON
}

Paulo Afonso de Araújo, UFJF

$\mathrm{R}$

ecentemente foi publicado pelas Edições Loyola, com tradução de Vinícius Honesko, o livro póstumo de Luigi Pareyson (1918-1991) Ontologia da liberdade: o mal e o sofrimento (1995) ${ }^{1}$. O volume foi projetado pelo próprio Pareyson e organizado por seus antigos alunos G. Riconda e G. Vattimo, com a colaboração de A. Magris e F. Tomatis. Composto por três partes (No caminho para a liberdade, A liberdade originária e a Liberdade e o nada), o denso conjunto reúne alguns ensaios, aulas e conferências em um todo bastante coerente, que representa o coroamento da especulação metafísica do importante filósofo italiano. Estas notas pretendem indicar brevemente: o lugar da obra no conjunto da trajetória pareysoniana (I); a caracterização da investigação que ela contém como interpretação do mito religioso (II); os principais núcleos de sua ousada e fecunda hermenêutica da experiência religiosa cristã (III); e os problemas que algumas criativas soluções apresentam (IV).

Pareyson define sua "ontologia da liberdade" como uma hermenêutica do mito, em particular do mito religioso; e ainda mais concretamente, como uma interpretação filosófica do cristianismo. Esta concepção pressupõe o existencialismo como matriz de pensamento, a compreensão da filosofia

${ }^{1}$ PAREYSON, Luigi. Ontologia da liberdade: o mal e o sofrimento. São Paulo: Edições Loyola, 2017, 411 p. 
como interpretação da verdade inexaurível e a escolha existencial pelo cristianismo como perspectiva sobre a verdade.

O horizonte especulativo da filosofia de Pareyson é o existencialismo entendido na perspectiva historiográfica da dissolução do hegelianismo, na qual, segundo ele, se debate a filosofia ao enfrentar os grandes problemas da realidade do finito, da possibilidade da filosofia e da validade do cristianismo ${ }^{2}$. Ao assumir a perspectiva do existencialismo, e repensar seus resultados, Pareyson apresenta uma original versão do personalismo, na qual a existência individual finita é pensada como positiva, mas não suficiente; como pessoa, isto é, como coincidência de relação a si e relação ao outro de si. Por esta concepção, finito e infinito são entendidos como realidades incomensuráveis, irredutíveis à dialética de complementaridade; consequentemente, a existência singular e concreta, irredutível a qualquer gênero ou totalidade, é concebida como síntese de singularidade e universalidade. A existência - sempre situada hic et nunc - é concebida como essencialmente aberta e intencionada ao ser, que embora não seja relativo estabelece a relação. A atividade humana - iniciativa iniciada - é entendida como síntese de receptividade e atividade e a liberdade humana é compreendida como resposta a um dom. Nesta perspectiva, a filosofia é concebida como interpretação pessoal, isto é, expressão de um tempo e de uma situação, que é dotada de uma validade especulativa, pois se encontra direcionada à verdade. Desta maneira, a filosofia é a interpretação, com validade especulativa, de uma pessoa situada que possibilita a afirmação, ao mesmo tempo, da unicidade da verdade - a verdade é única - , da singularidade das filosofias - cada filosofia é uma perspectiva pessoal sobre a verdade - e da unidade da filosofia - as várias filosofias, enquanto buscam a única verdade, estão em um diálogo ininterrupto. A matriz existencial-personalista permite ainda pensar o cristianismo como uma questão filosófica inevitável, diante da qual o homem atual, situado na crise da modernidade, se coloca e não pode não tomar uma posição. $\mathrm{Na}$ crise do cristianismo secularizado do mundo moderno, o homem de cultura deve dramaticamente decidir entre o reencontro do cristianismo religioso e o anti-cristianismo; e, decidindo-se pelo cristianismo, deve considerar seriamente a possibilidade de mergulho no ateísmo e niilismo, consequências inelutáveis do cristianismo secularizado.

A dissolução do hegelianismo legou ao existencialismo personalista de Pareyson a questão de como conciliar o condicionamento histórico da verdade com a exigência da mente humana de preservar o caráter absoluto da verdade. A resposta a esta importante questão o conduz ao desenvolvimento, através de uma intensa reflexão sobre a arte ${ }^{3}$, de uma

\footnotetext{
2 PAREYSON, L. Studi sull'Esistenzialismo. Florença: Sansoni, 1971. PAREYSON, L. Esistenza e Persona. Gênova: Il Melangolo, 1992.

${ }^{3}$ PAREYSON, L. Estética: Teoria da Formatividade. Petrópolis: Vozes, 1993.
} 
teoria geral da interpretação baseada em um personalismo ontológico ${ }^{4}$. A pessoa, enquanto coincidência de relação a si e relação ao outro de si, não apenas está em relação com o ser, mas é, ela mesma, esta relação. Enquanto constituída pela intencionalidade ontológica e por sua consciência do absoluto, a pessoa é, na sua concreta historicidade e liberdade, a única via à revelação da verdade ontológica. A verdade ontológica - absoluta e infinita não passível de objetivação acima da histórica - se dá única e tão somente em uma interpretação pessoal: a relação ontológica originária é necessariamente interpretativa e toda interpretação tem necessariamente um caráter ontológico. A verdade transcendente é a fonte inesgotável de sempre novas interpretações ou formulações, cada uma das quais pode possuir a verdade, desde que consiga ser revelação da verdade inexaurível e não apenas expressão do próprio tempo. Desta concepção decorre que, sendo a pessoa o órgão ou a via de acesso à verdade, depende de a liberdade pessoal abrir-se ou fechar-se à escuta da verdade: a verdade é confiada à nossa liberdade; não há saber da verdade sem a livre escolha da verdade, sem o empenho pessoal para atingi-la. A pessoa encontra-se diante da seguinte alternativa: consentir ao ser e tornar-se revelação pessoal da verdade e testemunha do ser; ou, refutar o ser, fechar-se em sua situação, e tornar-se ocultação da verdade e traição do ser. A verdade, cuja ulterioridade está fundada no caráter inexaurível do ser, está presente nas manifestações singulares sempre e apenas em modo implícito, isto é, como origem e estímulo de uma ulterior investigação, que nunca poderá desabrochar em uma explicitação completa. Entre a verdade e as suas formulações há uma relação de identidade e ulterioridade, pois cada interpretação autêntica - resultado do livre consentimento à revelação do ser - diz uma verdade com a qual se identifica, mesmo se continua a aludir à sua ulterior riqueza infinita. Assim, a filosofia entende-se como uma transcrição especulativa do pensamento revelador da verdade e testemunha do ser, em total contraposição à ideologia, entendida como mera expressão do tempo, falsificação da verdade e traição do ser.

A crise da cultura moderna é entendida por Pareyson como crise do cristianismo secularizado, como crise da síntese hegeliana de filosofia e religião. A ruptura da conciliação de filosofia e religião coloca em crise a ideia da conservação laicizada do cristianismo, como uma espécie de destino obrigatório, pois mostra que a secularização conduz, na verdade, ao anti-cristianismo, isto é, ao ateísmo e ao niilismo. Esta situação coloca de maneira incisiva a alternativa, entre o anti-cristianismo, representado pelo ateísmo e niilismo e o reencontro e recuperação - não um simples aggiornamento - do cristianismo religioso, como "fato eterno", irredutível à situação histórica e pessoal. O reencontro e recuperação do cristianismo como "fato eterno" não pode se dar no intimismo auto-satisfatório do

${ }^{4}$ PAREYSON, L. Verdade e Interpretação. São Paulo: Martins Fontes, 2005. 
cristianismo burguês - incapaz de considerar seriamente as razões de ateísmo e niilismo - , mas apenas em um cristianismo robusto e maduro que entenda o anti-cristianismo como o "penúltimo degrau" que, se devidamente superado, pode conduzir a uma profunda adesão existencial à fé cristã. Trata-se de uma escolha existencial fundamental que não é resultado de uma deliberação intelectual, mas uma aposta originária, mesmo se, enquanto escolha religiosa, nunca se pode distinguir claramente entre escolher e ser escolhido: de um ponto de vista cristão não tem sentido a questão se somos nós que escolhemos o Cristo ou o Cristo que nos escolhe. Como escolha existencial, análoga àquela presente em qualquer perspectiva filosófica - inclusive na racionalista, que aposta na pura razão - , a decisão a favor do cristianismo consiste na constituição de uma perspectiva pessoal sobre a verdade. Assim, para o filósofo crítico, intérprete da verdade e testemunha do ser, a escolha existencial da alternativa pró ou contra o cristianismo é questão filosófica absolutamente relevante, é inspiração originária e exigência última de seu pensamento, ou seja, é perspectiva sobre a verdade. Pareyson sempre afirmou sua escolha existencial pró cristianismo, de maneira que toda sua filosofia se situa, explícita e programaticamente, nesta escolha. Com efeito, a constitutiva intencionalidade ontológica da existência humana, a validade da pessoa, a transcendência e revelação da verdade, a centralidade da liberdade... são temas que brotam da escolha filosófico-religiosa a favor do cristianismo e encontram no cristianismo sua exigência última. A escolha a favor do cristianismo é para Pareyson, ao longo de todo seu Denkweg, uma profícua perspectiva de verdade.

Como ontologia existencial, a hermenêutica da experiência religiosa cristã converge para uma ontologia da liberdade ao ponto de com esta se identificar. O aprofundamento e radicalização da reflexão sobre a liberdade e o mal conduz a filosofia ao mito - sobretudo em sua forma religiosa -, entendido como experiência originária da verdade. Este apelo ao mito religioso requer, por sua vez, que a razão, sem se negar, reconheça seus limites e se coloque na atitude de escuta ativa diante do mistério da transcendência. A filosofia se torna, desta maneira, hermenêutica das interpretações originárias da relação constitutiva do homem com o transcendente, em particular, em nossa tradição, se faz interpretação das narrações da experiência religiosa cristã.

A liberdade se constitui em um fio condutor que atravessa toda produção filosófica de Pareyson, com crescente aprofundamento e radicalização de reflexões. No âmbito do personalismo ontológico, a atividade humana é, 
ao mesmo tempo, "iniciada", derivada de outro, e "iniciativa", pois inicia-se com um ato de liberdade. Trata-se de uma síntese de receptividade e atividade, de dom e consenso, que se baseia na constitutiva relação da pessoa com o ser. Desta maneira, entre a atividade originária e a atividade humana há um sútil diafragma entre duas atividades, isto é, entre duas liberdades - a liberdade que é o homem e a liberdade que é o próprio ser. Liberdade que, como primeira atividade do homem, é fundamentalmente entendida como escolha entre o consenso e a refutação do ser, entre a fidelidade e a traição ao ser, entre a revelação e o esquecimento da verdade. Na ontologia da liberdade, contudo, ser e liberdade são entendidos como idênticos e consequentemente a liberdade é concebida como o princípio único e ilimitado da realidade. Enquanto ilimitada, a liberdade é confinante com o nada, do qual emerge e cuja possibilidade conserva em si, mostrando desta maneira seu caráter essencialmente ambíguo. Esta ambiguidade, conexa à supressão do diafragma que separa a liberdade humana da liberdade originária, caracteriza tanto a liberdade humana quanto a liberdade divina: não apenas o homem pode escolher o mal, e efetivamente o escolheu, como também Deus não seria escolha originária do bem se não fosse vitória sobre a possibilidade do mal. A liberdade, tanto humana quanto divina, é sempre ao mesmo tempo início puro e escolha entre positivo e negativo. Como início puro, é ilimitada, arbitrária, absoluta e soberana: "só a liberdade precede a liberdade" e "só a liberdade segue a liberdade"; como escolha é, desde o início, opção entre duas possibilidades: a positiva (de começar) e a negativa (de não começar ou de cessar) e vice-versa. O contato originário da liberdade com o nada revela a realidade positiva do mal: a escolha efetiva do bem, não se dá sem a presença da possibilidade da escolha do mal - mesmo se superada e vencida - e a escolha efetiva do mal não se dá sem a presença daquela liberdade positiva que está em ato no próprio momento em que é negada e destruída. Assim, a radicalização da reflexão sobre a liberdade é intrinsecamente acompanhada por uma intensa reflexão sobre o escândalo do mal, entendido como fruto da liberdade humana, como deliberada instauração positiva de uma realidade negativa, como negação que é ao mesmo tempo destruição e autodestruição ${ }^{5}$. Mal que impregna profundamente a história humana e se mostra, à luz das forças humanas, incompreensível, insensato e injustificável; desafiando assim o sentido que o homem de maneira autônoma dá à sua existência. Com efeito, a única resposta possível ao mistério do mal pode ser encontrada na religião, no Deus cristão que se rebaixa e no sofrimento da cruz vence o mal. A radicalização da reflexão sobre a liberdade, conexa com a questão do mal, parte da escolha em favor do cristianismo - a centralidade da questão da liberdade - e desemboca no cristianismo - a interpretação filosófica do cristianismo. Trata-se de uma filosofia que, no interior da fé cristã, se

${ }^{5}$ PAREYSON, L. Dostoiévski: filosofia, romance e experiência religiosa. São Paulo: Edusp, 2012. 
coloca seriamente diante da questão existencial fundamental, que Schelling herda de Leibniz e transmite a Heidegger: "por que em geral algo é, por que não é o nada?"6

Filosofar no interior da fé cristã, como filosofia da liberdade, exige uma transformação da razão filosófica, exige que a filosofia reconheça seus limites diante do mistério, se autolimite e continue a pensar. A experiência humana de transcendência - dada sobretudo pela liberdade e pelo mal - revela ao homem a transcendência que caracteriza a realidade, suspensa de maneira inquietante no abismo da liberdade, e provoca tanto a maravilha quanto o horror, tanto a angústia quanto o estupor. A realidade, em si gratuita - não promovida pela possibilidade, nem reclamada pela necessidade -, revela-se ao homem como sem fundamento e a filosofia se percebe inapta para atingir, pelos próprios meios, o fundamento da totalidade daquilo que é. Assim, ao se confrontar com a questão existencial fundamental - "por que em geral algo é, por que não é o nada?" - a filosofia atinge seu limite extremo e entra em êxtase diante da transcendência da realidade. Mas, a transcendência da realidade mostra-se também como o pressuposto último de toda autêntica filosofia, pois o exercício crítico da razão - a delimitação dos limites da experiência humana do mundo conduz inevitavelmente ao confronto com a transcendência. Desta maneira, a experiência de transcendência, constitutiva do homem, e a transcendência da realidade, sua gratuidade e ambiguidade, podem ser vistas como abertura da filosofia à experiência religiosa, entendida como seu possível pressuposto crítico; aos olhos da experiência religiosa, as experiências humanas de transcendência e a gratuidade e ambiguidade da realidade, são possíveis habitações de Deus, isto é, lugares em que a transcendência divina não apenas se revela como o totalmente Outro, mas também como Aquele que pode vir ao encontro do homem. A experiência religiosa, sem triunfalismos, pode então oferecer à filosofia, que se disponha a escutá-la, uma resposta à pergunta existencial fundamental, uma compreensão da liberdade abissal, pressuposta pela realidade, e um sentido à existência, assumindo inclusive aquilo que se mostra como mais insondável, o mal. A experiência religiosa - se adequadamente interrogada e devidamente respeitada - pode socorrer a filosofia diante do báratro da razão.

Diante da experiência humana de transcendência e da transcendência da realidade, a existência, enquanto ontologicamente intencionada, mostra-se como consciência muda e real do ser, isto é, como consciência do ser efetivada apenas na douta ignorância, pois a consciência só pode possuir o ser na forma de ser por ele possuída. Mas, a consciência muda e real da posse originária do ser constitui o mito, entendido como narração reveladora da solidariedade originária do homem com a verdade, como narração, que unindo fantasia e pensamento, consegue revelar a verdade

\footnotetext{
${ }^{6}$ SCHELLING, F.W.J. Filosofia della Rivelazione. Milão: Rusconi, 1997, p. 406; 407.
} 
primigênia e originária de maneira muito mais adequada que o pensamento conceitual. O mito, entendido neste sentido superior, é considerado como especialmente apto a exprimir as verdades que se dão na experiência religiosa em geral - a experiência humana de tudo aquilo que é ulterior ao homem e que não é passível de objetivação - , e na experiência religiosa cristã em particular, isto é, na experiência humana da relação do homem com Deus e de Deus com o homem, onde Deus é livre, tanto de se dar na historicidade, quanto de instituir uma relação com o homem. Como narração poética de eventos originários, o mito revela, segundo a inventividade própria da imaginação humana, a verdade da transcendência em formas simbólicas ou figuras antropomórficas, respeitando a ulterioridade e não possibilidade de objetivação, que são próprias da divindade. Consequentemente, a linguagem simbólica, própria do mito, é a única capaz de revelar adequadamente a transcendência evitando o duplo risco da metafísica objetivante e do silêncio místico, da explicitação completa e da inefabilidade. O símbolo é concebido como dotado de duas características que o distinguem da alegoria e da metáfora: a "tautegoria" e a "inseparabilidade de fisicalidade e transcendência": a "tautegoria" faz do símbolo uma significação viva, pois o símbolo é a própria realidade simbolizada, presente na sua sensibilidade, viva na sua fisicalidade; a "inseparabilidade de fisicalidade e transcendência", por sua vez, faz do símbolo uma tensão entre presença e ulterioridade, pois o símbolo, ao mesmo tempo que une significante e significado, permite a abertura de um espaço em que a transcendência pode revelar-se sensivelmente como inexaurível. $\mathrm{O}$ símbolo, desta forma concebido, pode revelar adequadamente a transcendência da divindade à qual se refere a experiência religiosa, pois revela imediatamente a ulterioridade de Deus, preserva seu caráter indizível ao dizê-lo de maneira antropomórfica. Assim, a hermenêutica filosófica da experiência religiosa revela-se uma interpretação de um saber preexistente e originário, anterior à própria consciência do saber. Enquanto interpretação do mito, é hermenêutica de uma interpretação real e muda do absoluto; é rememoração daquilo que a existência já sabe e já possui, enquanto sabida e possuída pela transcendência à qual intenciona. Trata-se de uma hermenêutica que supõe uma ontologia existencial e por isso deve ser entendida como hermenêutica do cristianismo, pois nossa existência está imersa na tradição cristã. A hermenêutica existencial do mito, que pode socorrer a filosofia no báratro diante da razão, é na verdade uma interpretação filosófica das narrações da experiência religiosa cristã.

A hermenêutica filosófica do cristianismo elaborada por Pareyson diz respeito sobretudo a três grandes núcleos das narrações da experiência religiosa cristã: o texto de Ex. 3, 14 interpretado no sentido da revelação 
de Deus como liberdade originária; o pecado original interpretado como responsável pela existência do mal real no mundo, embora sua origem esteja no próprio Deus; e o sacrifício de Cristo na cruz interpretado como única resposta possível ao horror do mal, enquanto libertação pelo sofrimento do mal real.

A passagem de Ex. 3, 14 permitiria, segundo Pareyson, a interpretação de Deus como liberdade originária - Deus é início absoluto - é vontade de existir e ser vitória sobre o nada e sobre o mal - Deus é escolha originária do bem. Interpretar Deus como início absoluto, significa pensar, antes de tudo, que o ato eterno da criação tenha sido precedido, em Deus, pelo seu ato eterno de autogênese; e, em seguida, que este ato de teogonia introduz na eternidade de Deus uma temporalidade muito especial, expressa na fórmula paradoxal de "Deus antes de Deus". Interpretar Deus como escolha originária do bem, por sua vez, significa pensar que a escolha é o início eterno e absoluto de Deus: Deus é a eterna escolha do ser e exclusão do não ser, é a escolha eterna do bem e vitória sobre o nada e sobre o mal. Entender Deus como escolha originária entre positivo e negativo não significa afirmar a preexistência, respeito a Deus, de ser e não ser, de bem e mal, pois o ato com o qual Deus dá origem a si mesmo, escolhendo ser, é o mesmo ato que institui a alternativa entre o positivo escolhido e o negativo descartado, entre o bem iniciado e o mal vencido. Mas, conceber Deus como liberdade originária - ao mesmo tempo início absoluto e escolha entre positivo e negativo - implica conceber Deus como um Deus dialético, pois o mesmo ato de gerar a si mesmo como escolha do bem inaugura Nele uma dialética entre o ser, afirmado, e o não ser, descartado, entre o bem real escolhido e o mal possível recusado.

Deus, embora dialético, é interpretado como positividade originária, isto é, como ato originário no qual o nada e o mal foram vencidos ab aeterno. Contudo, a escolha originária e definitiva do bem é inseparável da instauração da possibilidade do mal. $\mathrm{O}$ mal, mesmo se vencido originariamente, surge como uma alternativa possível, instituída pela liberdade divina no próprio momento em que esta se escolheu como liberdade positiva. A autogênese de Deus, enquanto escolha originária do bem, deu origem ao mal como mera possibilidade vencida e superada eternamente. Esta mera possibilidade, presente em Deus como um passado possível que nunca foi presente, é a origem do mal que se torna realidade com a queda original do homem criado à imagem e semelhança de Deus, como livre. O pecado original é desta maneira entendido como um ato livre negativo - oposto ao ato livre positivo de Deus -, que desperta a possibilidade do negativo que em Deus estava totalmente adormecida e dominada. Assim, Deus é a origem do mal e o homem seu único autor. O pecado original - rebelião à positividade de Deus e realização da negatividade que Deus havia recusado - inaugura a história humana, marcada pela dialética entre o bem e o mal reais, onde o mal não é apenas uma possibilidade vencida e 
superada, mas uma presença real, uma força que combate contra o bem e poderia, inclusive, ter a última palavra.

A irrupção na história, inaugurada pelo pecado original, do livre ato redentor de Deus instaura uma nova dialética que atravessa a dialética de bem e mal reais, a dialética do sofrimento, que a todos envolve não apenas na comum solidariedade da culpa, mas também na comum solidariedade da expiação. Esta dialética do sofrimento culmina no Cristo crucificado, onde Deus assume em si mesmo o mal real para redimir o homem, repetindo desta maneira a vitória originária sobre o nada e o mal. A cruz de Cristo é, desta maneira, interpretada como o lugar em que Deus assume a tragédia humana como tragédia divina, como o lugar em que Deus luta consigo mesmo e nega a si mesmo, travando em seu interior a última e definitiva batalha contra o mal. O silêncio de Deus, que abandona o Filho na cruz, e a angústia e desespero do Cristo, Filho que se fez homem e foi abandonado pelo Pai na hora da morte, constituem, desta maneira, o momento ateu que é introduzido na própria divindade ao assumir em si o mal real. Mas, ao assumir o mal real Deus manifesta também, através do sofrimento da cruz, todo seu poder: Deus, a absoluta positividade, assume em Jesus Cristo toda negatividade humana, a afronta em uma dolorosa e trágica luta e a vence definitivamente. Desta maneira, a cruz de Cristo, interpretada como repetição e renovação da vitória originária de Deus sobre o nada e o mal, é concebida como a única resposta possível ao horror do mal que o homem, único responsável pela sua existência, diariamente experimenta.

Através desta ousada e arriscada interpretação das narrações da experiência religiosa cristã, Pareyson pretende responder à questão fundamental da filosofia - "por que em geral algo é, por que não é o nada?". Contudo, o confronto desta interpretação com a teologia e exegese cristãs, sensíveis às questões suscitadas por Pareyson, revela que a hermenêutica do cristianismo, levada a efeito na ontologia da liberdade, não respeita nem explora suficientemente, como se propõe, a riqueza do dado cristão.

O texto Ex. 3, 14, que permitiria a interpretação de Deus como liberdade, está inserido em um contexto de revelação histórico-salvífica: Deus chama Moisés e o envia para a libertação de seu povo que se encontrava reduzido à escravidão pelo faraó. Neste contexto, a revelação do nome pretende indicar a garantia do compromisso de Iahweh com seu povo, é comunicação da livre proximidade salvífica de Iahweh junto a seu povo. Desta maneira, com base em Ex. 3, 14, não é possível afirmar que Deus é a liberdade originária, nem é plausível a dedução de uma teogonia, pois 
este texto não nos oferece nenhuma definição ontológica de Deus, nem nos sugere alguma dialética interior ao divino. Além disso, o dado bíblico referente às origens, não nos autoriza a nenhuma especulação sobre "Deus antes de Deus", sobre Deus antes da criação. Para as narrações da experiência religiosa cristã, com efeito, Deus se revela antes de tudo como amor: é no amor que Ele cria o outro de si; é na liberdade do amor que Ele quer, cria e suscita relações de amor; e é por amor que Ele corre o risco de ser refutado. A narração cristã da origem, elaborada a partir da páscoa, entende a criação no âmbito das relações trinitárias, conjugando a ontologia do amor com a ontologia trinitária: o Filho amado pelo Pai é mediador na Trindade criadora. Assim, a concepção pareysoniana de Deus como liberdade originária, longe de ser uma hermenêutica das narrações da experiência religiosa cristã, revela-se uma projeção nos textos da tradição religiosa cristã de uma ontologia elaborada a partir de Plotino e Schelling: Deus não é um Uno solitário que em um ato de vontade decide ser, mas é amor (cf. 1 Jo. 4, 8.16) que tanto amou o mundo que por ele entregou seu Filho amado (cf. Jo. 3, 16; Mt. 17, 5).

Ao pensar Deus como liberdade originária, como início absoluto e escolha entre positivo e negativo, Pareyson acaba concebendo o Deus cristão como um Deus dialético, que embora seja positividade absoluta conserva em si a negatividade como mera possibilidade vencida ab aeterno. O pecado original é considerado um ato livre do homem que reaviva aquela negatividade não escolhida por Deus e, desta forma, evidencia, enquanto escolha oposta à escolha divina, o conflito originário interior ao divino, quando o "Deus antes de Deus" escolheu ser. Esta interpretação, associada à interpretação do ato redentor de Deus, acaba fazendo da queda original um momento teogônico, pois obriga Deus a repetir e renovar sua eterna autogênese. Assim, pelo pecado original o homem se torna uma espécie de anti-Deus, um Prometeu extremamente potente que se eleva até seu criador e introduz a negatividade real na positividade divina, e, com este ato terrificante, inaugura a história. $\mathrm{O}$ dado cristão, contudo, não autoriza esta interpretação colorida de gnosticismo. Para as narrações da experiência religiosa cristã, com efeito, em Deus não há nem pode haver a mínima sombra do mal, porque ele é luz (cf. 1 Jo. 1, 5). Deus é o Senhor Uno e Trino, que quis e constituiu o homem, sua criatura, como sujeito de uma relação de amor, na qual Deus se propõe e o chama ao seu convívio. $\mathrm{O}$ pecado original, por sua vez, é a decaída ontológica desta relação dialógica de amor que, contudo, não cancela a relação criador-criatura, não faz do homem um anti-Deus. $\mathrm{O}$ cristianismo fala do pecado original para anunciar a excesso desmedido da graça, pois onde abundou a culpa superabundou a graça (cf. Rm. 5, 20). Além disso, para o "mito" cristão Deus é determinado unicamente pela liberdade de seu amor, não pelo pecado do homem.

O dado cristão revela também todo sofrimento e angústia do Filho crucificado, que na agonia da cruz grita a Deus as primeiras palavras do Sl. 22: 
“Deus meu, Deus meu, por que me abandonaste?" (Mc. 15, 34; Mt. 27, 46). Este grito de abandono deve, contudo, ser interpretado em sentido trinitário: a cruz só pode ser compreendida adequadamente como um evento entre Pai e Filho, distintos e unidos no Espírito Santo. Na perspectiva trinitária, com efeito, o versículo do salmo 22, associado à oração de entrega (Sl. $31,6)$, pronunciada por Jesus, segundo Lc. 23, 46, pode ser interpretado, ao mesmo tempo, como a suprema entrega do Pai, como auto-entrega do Filho e como entrega do Espírito que o Filho faz ao Pai. Desta maneira, o Pai - que entrega o Filho à morte dos rejeitados - com o abandono do Filho na cruz se introduz na terra dos sem Deus e se faz Pai de todos os abandonados e malditos; e o Filho - entregue à morte de cruz - se torna irmão e salvador de todo pecador, abrindo desta maneira aos sem Deus a paternidade divina. Estas entregas não têm caráter de necessidade, não são determinadas pelo pecado do homem, mas são livres doações realizadas por amor; por elas, não é o mal que se introduz em Deus, mas, ao contrário, Deus que no Filho entra no exílio dos malditos e, no abandono do Filho, se revela o Pai de todos abandonados. O processo pelo qual estas entregas se dão é marcado por uma dor profunda - a dor do Pai pela rejeição e abandono do Filho à morte -, que incide sobre o próprio ser de Deus; mas se trata de uma dor que advém do excesso de seu amor, não do mal real que nele se introduz. Deus sofre pelo pathos de seu amor. A certeza deste amor, que a cruz de Jesus revela, oferece ao homem uma resposta prática, não uma explicação, ao horror do mal.

Não obstante estes problemas aqui indicados, Pareyson tem muitos e admiráveis méritos em sua corajosa e radical Ontologia da Liberdade: as narrações da experiência religiosa cristã, vencidas as hodiernas tentações preconceituosas e superficiais, muito podem oferecer a uma filosofia vigorosa, verdadeiramente aberta e disposta a refletir com seriedade as questões do mal, do sofrimento e da liberdade, que tanto nos angustiam. 